\title{
Antral Follicle Count
}

National Cancer Institute

\section{Source}

National Cancer Institute. Antral Follicle Count. NCI Thesaurus. Code C97213.

The number of small ovarian follicles (approximately 2-8 $\mathrm{mm}$ in diameter) that can be detected and counted with transvaginal ultrasonography, to determine the remaining fertility potential in a woman. 